\author{
КОНСТАНТИНОВ И.С. \\ Гумберидзе М.Э. \\ Жуков А.В.
}

1) проректор по научной и инновационной деятельности, доктор технических наук, профессор.

Белгородский государственный национальный исследовательский университет, Россия, 308015,

г. Белгород, ул. Победы, 85. e-mail: konstantinov@bsu.edu.ru

2) старший преподаватель кафедры математического и программного обеспечения информационных систем.

Белгородский государственный национальный исследовательский университет, Россия, 308015,

г. Белгород, ул. Победы, 85. e-mail: gumberidze@bsu.edu.ru

3) аспирант кафедры математического и программного обеспечения информационных систем НИУ БелГУ, заместитель исполнительного директора ООО «Бюджетные и Финансовые Технологии», 308001, г. Белгород, пл. Литвинова, 9. e-mail: Zhukov_A@bsu.edu.ru

\begin{abstract}
Аннотация
В работе говорится о важности внедрения информационных технологий в образовательный процесс. Рассматриваются проблемы, которые возникают из-за новых вызовов современного информационного общества. На примере работы, которая внедрена на кафедре математического и программного обеспечения информационных систем мы предлагаем комплексный подход к организации учебного процесса по дисциплине «Избранные вопросы математической логики».

Актуальность данной статьи в том, что проверка и оценка знаний, умений и навыков владения математической логикой студентами технических специальностей в вузе является очень важной и необходимой составной частью учебного процесса, а овладение методикой проверки знаний является одной из важных и трудных задач, стоящих перед преподавателем. Авторы, пользуясь современными образовательными технологиями упрощают эту проблему, при этом качество остаточных знаний и адаптация к среде и профессии дают положительный и качественный результат.
\end{abstract}

Ключевые слова: информация; отражение; актуальность; проблема; дисциплина; знания; коммуникативные действия; самоактуализация; профессионал.

\title{
UDC 519.718.7
}

Konstantinov I.S. Gumberidze M.E. Zhukov A.V.

\section{CHARACTERISTICS OF ORGANIZATION OF EDUCATIONAL PROCESS FOR MASTER DEGREE STUDENTS}

1) Doctor of Technical Sciences, Professor, Vice-Rector for Research and Innovation, Belgorod State National Research University, 85 Pobeda St., Belgorod, 308015, Russia e-mail: konstantinov@bsu.edu.ru

2) Gumberidze Marianna Elgudzhevna, Senior Teacher, Department of Mathematical and Software Support of Information Systems, Belgorod State National Research University, 85 Pobeda St., Belgorod, 308015, Russia e-mail: gumberidze@bsu.edu.ru

3) Zhukov Alexey Vladimirovich, Post-graduate Student, Department of Mathematical and Software Support of Information Systems, Deputy Executive Director of "The Budget and Financial Technologies" Ltd., 9 Litvinova St., Belgorod, 308001, Russia.e-mail:Zhukov_A@bsu.edu.ru

\begin{abstract}
The article discusses the importance of introduction of information technologies in educational process. The article covers the problems which arise due to new challenges of the modern information society. On the example of the work which is introduced at the Department of Mathematical and Software Support of Information Systems, the authors offer an integrated
\end{abstract}


approach to the organization of educational process for the discipline "Selected questions of mathematical logic". The article is of immediate interest due to the fact that evaluation and assessment of knowledge and skills of mathematical logic in university students of technical specialties is a very important and necessary component of educational process. Mastering a technique of assessment of knowledge is one of the important and difficult tasks of any teacher. Using modern educational technologies, the authors solve this problem, at that, the quality of residual knowledge and adaptation to a professional environment produce a positive and qualitative result.

Keywords: information; answer; relevance; problem; discipline; knowledge; communicative actions; self-updating; professional.

\begin{tabular}{lccr}
\multicolumn{2}{c}{ Современное } & \multicolumn{2}{c}{ исследование } \\
инфонмацимена \\
Информации.
\end{tabular}
предполагается, что информация, также, как и энергия, существует во всех сферах и фрагментах мироздания, является характеристикой всех материальных систем. Понятие информации отражает как объективно-реальное, не зависящее от субъекта свойство объектов неживой и живой природы, общества, так и свойства познания, мышления. Разнообразие объективной реальности отражается сознанием человека, и в этом смысле оно становится отраженным разнообразием, свойством сознания. Информация, таким образом, присуща как материальному, так и идеальному. Она применима и к характеристике материи, и к характеристике сознания. Если объективная (и потенциальная для субъекта) информация может считаться свойством материи, то идеальная, субъективная информация есть отражение объективной, материальной информации [9].

Информация превратилась в экономическую категорию, так как быстро развивается информационный рынок и бизнес. Всеобщий характер информатизации общества и проникновение во все сферы жизни связаны с развитием компьютерных сетей и цифровых технологий.

Формируется новая научная парадигма и методология научных исследований.

Возникает новый комплекс проблем информационной безопасности, о которых человечество ранее не имело ни малейшего представления.

Все эти проблемы еще не нашли отражения в массовом сознании, которое существенным образом отстает от темпов развития цивилизации [3].

Важность изучения фундаментальных проблем информации в системе образования еще недостаточно осознана, хотя актуальность такого изучения не вызывает сомнений.
Две проблемы: обеспечение доступности информации для всех членов общества и овладения информацией являются сегодня принципиально важными и имеющими стратегический статус для развития страны.

Проблема владения информацией, еe стратегическая важность для развития общества нам представляется недооценена.

Высокие технологии, используемые в производстве, повышают эффективность производства, внедрение высоких технологий в энергетике дает существенную отдачу в энергосбережении, а также в области безопасности сложных технологических объектов и систем.

Таким образом, информационные аспекты инновационного развития играют важную, и даже ключевую, роль в решении стратегических задач системной модернизации любого государства.

Характер проблематики наук об овладении современных накопленных знаний требует необходимость комплексного изучения данной проблемы не только в рамках академической науки, но также и в системе образования. Современное состояние в математике и информатике не оставляет сомнений в том, что можно сформулировать математически большинство положений, связанных с передачей информации. В настоящее время наиболее быстрые способы обучения, использующиеся в промышленности, основаны на специально разработанных методиках и соответствующих им математическим моделях. Компьютерное обучение операторов на автоматизированных тренажерных системах полностью изучено, разработаны теоретические, систематические, количественные методы, позволяющие в короткие сроки обучить операторов разных промышленных оборудовании действиям в штатных и нештатных ситуациях и довести эти умения до автоматизма. Этому способствует простота модели обусловленное небольшим числом параметров, ситуаций, высокой степени 
мотивации обучаемого. Наиболее эффективны компьютерные обучающие системы тогда, когда речь идет об обучении определенным навыкам. Используемые при этом компьютерные обучающие системы являются автоматизированными, в простейших случаях они выполнены с помощью обычной автоматики, в сложных - основаны на использовании компьютеров. Широко используются тренажерные системы и в области образования. Общие методологические принципы и подходы для изучения сложных систем и этапы их исследования требуют особого подхода в технологии образования.

«Целью научных знаний должно быть направление ума таким образом, чтобы он выносил прочные и истинные суждения о всех встречающихся предметах» и «Мало иметь хороший ум, главное - хорошо его применять» [10]. Как же прав и современен Рене Декарт и сегодня!

Математическая логика как раздел математики является одной из дисциплин, обеспечивающих фундаментальность образования инженера.

Данная дисциплина рекомендована для подготовки специалистов по направлениям «Прикладная информатика», «Информационные системы и технологии», «Математика», «Программная инженерия», «Математическая лингвистика» и т.д.

Дисциплина «Избранные вопросы математической логики» является логической основой понимания сущности доказательств и их логического строения, изучения аксиоматических математических теорий из разных областей математики, а также теоретической основой логической составляющей обучения математике. Изучение дисциплины является базой для дальнейшего освоения студентами курсов профессионального цикла. Знания, умения и навыки, полученные студентами в результате усвоения материала дисциплины, могут быть использованы ими во всех видах деятельности в соответствии с Государственным образовательным стандартом высшего профессионального образования.

Цели и задачи учебной дисциплины требования к результатам освоения дисциплины: ознакомление студентов с её важнейшими разделами математической логики для применения полученных знаний в решении практических задач, повышение уровня математической культуры, развития логичности и конструктивности мышления, формирования систематизированных знаний в области математической логики, представлений о проблемах оснований математики и роли математической логики в их решении; развитие логического мышления, логической культуры, логической интуиции.

Работа, которая ведется авторами на базе НИУ БелГУ, Института информационных технологий и естественных наук, кафедры математического и программного обеспечения информационных систем, попытка внедрения новых образовательных технологий в образовательный процесс. Дисциплина «Избранные вопросы математической логики» включена в математический и общий естественнонаучный цикл программы магистрантов по специальности «Математика и компьютерные науки». Данную дисциплину на кафедре ведут преподаватели: д.т.н., профессор Константинов И.С. (ведущий преподаватель), ст. преподаватель Гумберидзе М.Э. и аспирант Жуков А.В.

Задачи дисциплины «Избранные вопросы математической логики»:

- освоение методологии исследования математической теории с точки зрения математической логики и решение широкого круга задач компьютерных наук;

- формирование представлений о противоречивости, непротиворечивости, полноте математической теории, зависимости или независимости положений, положенных в основу, рассматриваемой теории

- формирование современного взгляда на основания математики;

- освоение методологии исследования формальных доказательств;

- формирование и развитие логического мышления;

- освоение магистрантами математического аппарата, применяемого в теории логического вывода, машинного доказательства теорем, для проектирования логических устройств в некоторых специальных дисциплинах.

Мы постарались в работе следовать классическим традициям российской математической школы, не забывая, при этом новые образовательные стандарты и информационные технологии.

Так нами запланированы съемки мини фильмов (видеороликов), где ведущий преподаватель кратко знакомит с основными 
задачами, которые он определяет на предстоящее лекционное занятие. Наличие внутренней сети университета позволяет выполнить рассылку всем студентам группы. Предполагается, что студенты, будучи оповещены о теме лекции, постараются познакомиться с материалом, подготовить, вопросы по текущей проблеме.

В современной педагогике приоритетом общего образования становится развитие личности через формирование универсальных учебных действий.

Коммуникативные действия обеспечивают возможности сотрудничества: умение слышать, слушать и понимать партнёра, планировать и согласованно выполнять совместную деятельность, распределять роли, взаимно контролировать действия друг друга, уметь договориться, вести дискуссию, правильно выражать свои мысли, оказывать поддержку друг другу и эффективно сотрудничать как с преподавателем, так и со сверстниками [1].

Для успеха студентам необходимо уметь, при планировании учебного сотрудничества: задавать вопросы, необходимые для организации собственной деятельности и сотрудничества с партнером; определять цели, функции участников, способы взаимодействия; договариваться о распределении функций и ролей в совместной деятельности.

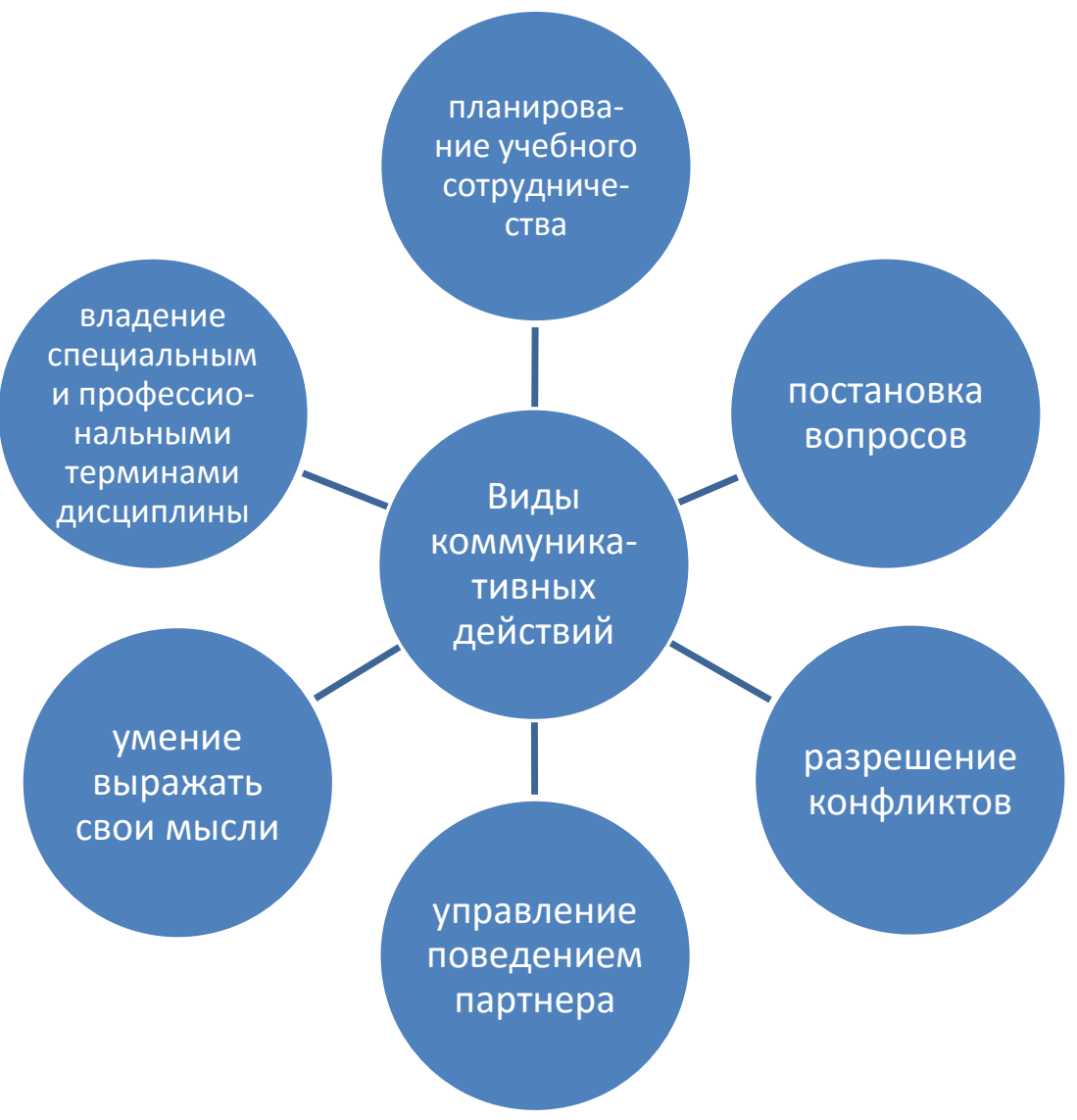

Puc. Виды коммуникативных действий

Fig. Types of communication activities

В плане инициативного сотрудничества: ставить вопросы, обращаться за помощью, формулировать свои затруднения; предлагать помощь и сотрудничество; проявлять активность во взаимодействии для решения коммуникативных и познавательных задач.

В рамках взаимодействия: формулировать собственное мнение и позицию, задавать вопросы; строить понятные для партнера высказывания; строить монологическое высказывание; вести устный и письменный диалог в соответствии с грамматическими и синтаксическими нормами родного языка, слушать собеседника.

В рамках сотрудничества: определять общую цель и пути ее достижения; осуществлять 
взаимный

контроль;

прогнозировать

возникновение конфликтов при наличии разных точек зрения; разрешать конфликты на основе учета интересов и позиций всех участников; координировать и принимать различные позиции во взаимодействии [4].

Во время чтения лекций, преподаватель может выбирать пользоваться ли ему возможностями современной электронной доски (так как на базе университета есть несколько аудиторий предоставляющие эту возможность и подготовлены презентации) или выбирать аудиторию, где есть возможность классическим способом проводить объяснение изучаемой темы (в связи с этим заранее планируется проводить часть практических занятий в компьютерных классах).

На практических занятиях студентам предоставляется больше свободы общения и выбора из базы задач по текущему материалу (задачи рассылаются по электронной почте группе), какие именно будут рассмотрены с преподавателем. Обычно, студенты сами решают и выбор падает на задачи, вызвавшие затруднения при самостоятельном решении.

Нередко, лектор во время проведения занятия, использует заранее подготовленные вопросы, которые представлены в виде небольшого формата раздаточного материала (не более 3 вопросов). Вопросы, составлены по текущей лекции и преподаватель, достаточно быстро получает информацию о том, насколько внимательно аудитория слушала новый материал и насколько хорошо он был усвоен. Работая в тесном сотрудничестве с преподавателем, который ведет практические занятия и аспирантом, который отвечает за создание базы задач в электронном виде, тестов и т.д., ведущий преподаватель может достаточно гибко менять свое направление, не выходя за рамки рабочей программы, уделять больше времени и закрепить типовыми задачами новый материал во время практических занятий.

На практических занятиях используем групповые формы работы. Студентов формируем в группы и это дает возможность ребятам научиться совместному решению поставленных задач. Включаем соревновательные элементы. Баллы, полученные на таких практических занятиях, учитываются во время зачета.

Подготовлен материал для выполнения работ с привлечением ПК. Тесты в электронном и бумажном виде. Тестирование проводится после завершения изучения каждого нового раздела дисциплины.

Теория излагается преднамеренно кратко, в многочисленных примерах обобщаются и развиваются ключевые идеи курса и каждая глава снабжена приложением теории к практике. Приложения наглядно демонстрируют как математическая логика решает задачи компьютерных наук.

Цель дальнейшего совершенствования работы-мотивация магистранта.

Поле - это сочетание факторов внешней и внутренней ситуации, то есть окружения и субъекта [6, С. 76-79]. К. Левин считал, что потребности личности всегда находятся в связи друг с другом. При этом квазипотребности могут обмениваться энергией, являясь коммуникацией заряженных систем. Такая коммуникация способна делать поведение человека более гибким, помогает в разрешении конфликтов, преодолении различных барьеров и в нахождении выходов из трудных ситуаций [7, С. 156-158]. Познание сложный путь, мы стремимся в своей работе не только обучить, но и помочь понять магистранту причину, понимание своих способностей и как энтузиазм, настойчивость, заинтересованность влияет на дальнейшую его деятельность. Мы хотим своей работой выполнить роль «пускового механизма» для процесса самоактуализации [5, С. 105-107].

При изучении дисциплины- внимание учащегося обращено на её прикладной характер, на то, где и когда изучаемые теоретические положения, и практические навыки могут быть использованы в будущей практической деятельности.

Так как магистр должен быть готов к выполнению исследовательской деятельности в областях, использующих математические методы и компьютерные технологии, созданию математических моделей процессов и объектов, разработке программ решения соответствующих задач естествознания, техники и управления, проектно-конструкторской, экономической, а также должен быть готов к деятельности, требующей углубленной фундаментальной и профессиональной подготовки, мы сталкиваемся c необходимостью включать информационные аспекты инновационного обучения. При малом количестве аудиторных занятий планирование образовательного процесса становится одной из ключевых задач учебного процесса. 
Многие студенты могут выбрать своей дальнейшей профессией педагогическую деятельность. Процесс выявления комплекса условий необходимых для этого также стоит во главе задач, которые мы определяем для себя. Мы применяем в образовательной практике следующие педагогические условия: осознание будущей профессиональной деятельности, развитие личности и обучение носит междисциплинарный характер [8].

Вызовы современного

активно развивающегося мира заставляют нас все время находить новые образовательные технологии, учитывать особенности нового двухуровневого стандарта высшей школы и не забывать о том, что организация учебного процесса должна обеспечить переход обучающегося из позиции студента в позицию профессионала, «трансформацию учебной деятельности в профессиональную» [2].

\section{Список литературы}

1. А.Г. Асмолов, Г.В. Бурменская, И.А. Володарская и др. Как проектировать универсальные учебные действия в начальной школе: от действия к мысли: пособие для учителя / под ред. А.Г. Асмолова. - М.: Просвещение, 2010.

2. Выготский Л.С., Бакшеева Н.А. Развитие мотивации студентов в контекстном обучении. - М., 2000, C.79.

3. Колин К.К. Информационные технологии катализатор процессов развития современного общества. / К.К. Колин // Информационные технологии. - 1995, - № 10. - С. 2-8.

4. Корсакова И.В., Гумберидзе М.Э. Использование информационных технологий для обучения детей младших классов общеобразовательных учреждений Сборник научных трудов по итогам международной научнопрактической конференции. 2015. С. 74-76.

5. Крайг, Г. Психология развития / Г. Крайг СПб.: Изд-во «Питер», 2000. - 992 с.

6. Макклелланд, Д Мотивация человека / Макклелланд Д. - СПб.: Изд-во «Питер», 2007. - 672 с.
7. Маклаков, А.Г. Общая психология / А.Г. Маклаков. - СПб.: Изд-во «Питер», 2001. - 592 с.

8. Смирнов, В.И. Общая педагогика в тезисах, дефинициях, иллюстрациях/В.И. Смирнов. - М.: Педагогическое общество России, 1999. - 416 с.

9. Урсул А.Д. Природа информации. Философский очерк / А.Д. Урсул. - М.: ПОЛИТИЗДАТ. - 1968. - 288 с. (Немецкий перевод: Ursul A.D. Information. EinephilophischeStudie. Berlin: Dietz Verlag. 1970).

10. Афоризмы великих людей. URL: http://www.wisdoms.ru/pavt/p73.html. (дата обращения 10.05.2016)

\section{References}

1. Asmolov A.G, Burmenskaya G.V., Volodarskaya I.A. et al. How to Plan Universal Learning Activities in Primary Schools: from Action to Thought: A Guide for Teachers / Ed. by A.G. Asmolov. M.: Education, 2010.

2. Vygotsky L.S., Baksheeva N.A. Development of Aspirations of Students in Contextual Training. M. 2000. P.79.

3. Colin K.K. Information Technology - the Catalyst of Processes of Development of the Modern Society. / K.K. Colin // Information Technologies. 1995. № $10 . \mathrm{Pp} .2-8$.

4. Korsakova I.V., Gumberidze M.E. The Use of Information Technology for Education of Children of Junior Classes of Educational Institutions. Collection of Scientific Papers on the Results of the International Scientific-Practical Conference. 2015. Pp 74-76.

5. Craig, G. Developmental Psychology / T. Krayg$\mathrm{SPb}$ Univ. Of «Peter», $2000.992 \mathrm{p}$

6. McClelland. Human Motivation D / D. McClelland-Petersburg Univ. Of "Peter", 2007. 672 p.

7. Maklakov A.G. General Psychology / A.G. Maklakov. SPb Univ. Of «Peter», 2001. 592 p.

8. Smirnov V.I. General Pedagogy in Thesises, Definitions, Illustrations / V.I. Smirnov. M.: Russian Society of Teachers. $1999.416 \mathrm{p}$.

9. Ursul A.D. The Nature of the Information. Philosophical Essays / A.D. Ursul. M.: Politizdat. 1968. 88. (transl. from German: Ursul A.D. Information Einephilophische Studie Berlin: Dietz Verlag in 1970.).

10. Aphorisms greats. URL: http://www.wisdoms.ru/pavt/p73.html. (date of access: May 10, 2016). 